\title{
L2 Learner Production and Processing of Collocation: A Multi-study Perspective
}

\section{Anna Siyanova \\ Norbert Schmitt}

\begin{abstract}
This article presents a series of studies focusing on L2 production and processing of adjective-noun collocations (e.g., social services). In Study 1, 810 adjective-noun collocations were extracted from 31 essays written by Russian learners of English. About half of these collocations appeared frequently in the British National Corpus (BNC); one-quarter failed to appear in the BNC at all, while another quarter had a very low BNC frequency. Based on frequency data and mutual information (MI) scores, it was discovered that around $45 \%$ of all learner collocations were, in fact, appropriate collocations, that is, frequent and strongly associated English word combinations. When the study data were compared to data from native speakers, very little difference was found between native speakers (NS) and non-native speakers (NNS) in the use of appropriate collocations. Unfortunately, the high percentage of appropriate collocations does not mean that NNSs necessarily develop fully native-like knowledge of collocation. In Study 2, NNSs demonstrated poorer intuition than NS respondents regarding the frequency of collocations. Likewise, Study 3 showed that NNSs were slower than NSs in processing collocations. Overall, the studies reported here suggest that L2 learners are capable of producing a large number of appropriate collocations but that the underlying intuitions and the fluency with collocations of even advanced learners do not seem to match those of native speakers.
\end{abstract}

Keywords: collocation, learner corpus, frequency, L2 exposure, processing speed

Résumé : Cet article présente une série d'études portant sur la production et le traitement des collocations de type adjectif-nom en langue seconde (L2) (telles que social services en anglais). Dans la première étude, 810 collocations adjectif-nom ont été extraites de 31 compositions rédigées par des apprenants d'anglais d'origine russe. La moitié environ de ces collocations paraissait fréquemment dans le corpus national britannique, un quart n'y paraissait nullement, et un dernier quart présentait une fréquence très basse d'apparition dans le corpus national britannique. À partir des données de fréquence et des scores d'information mutuelle, il a été découvert 
qu'environ $45 \%$ des collocations des apprenants étaient en fait des collocations appropriées, soit des combinaisons courantes de mots anglais présentant de fortes associations. Lorsque les constatations de cette étude ont été comparées aux résultats d'études effectuées auprès de locuteurs natifs, on a relevé très peu de différences dans l'emploi des collocations appropriées entre locuteurs natifs et non natifs. Toutefois, malheureusement, le fort pourcentage de collocations appropriées ne signifie pas que les locuteurs non natifs parviennent nécessairement à une connaissance tout à fait native des collocations. Dans la deuxième étude, des locuteurs non natifs ont fait preuve d'une moins bonne intuition que des participants natifs concernant la fréquence des collocations. De même, une troisième étude a révélé que les non natifs effectuaient le traitement des collocations plus lentement que les natifs. En général, les recherches présentées dans cet article suggèrent que les apprenants de L2 sont capables de produire un grand nombre de collocations appropriées, mais que leur intuition et leur facilité dans l'emploi des collocations ne semblent pas comparables à celles des locuteurs natifs, et ce, pas même dans le cas d'apprenants de niveau avancé.

Mots clés : collocation, corpus d'apprenants, fréquence, exposition à la L2, vitesse de traitement

\section{Introduction}

The appropriate use of collocation (word combinations such as strong tea, fair complexion, petty crime) is now widely accepted as a prerequisite for proficient language use (e.g., Cowie, 1998; Sinclair, 1991; Wray, 2002). However, it has also been well established that L2 learners often have problems with collocations in their written and spoken language (Granger, 1998; Howarth, 1998; Nesselhauf, 2003, 2004). Several researchers have suggested that L2 learners rely heavily on creativity and thus make 'overliberal assumptions about the collocational equivalence of semantically similar items' (Wray, pp. 201-202). That is, when two words are synonymous, such as surgery and operation, learners are likely to assume their equally appropriate status in a collocation like plastic surgery and may thus produce an atypical English combination like plastic operation. Skehan (1998) and Foster (2001) propose that non-native speakers (NNSs), unlike native speakers (NSs), construct a great proportion of their language from rules rather than from lexicalized routines. In relation to collocation, this means that learners often acquire words individually, without taking note of their immediate environment, and that, when trying to produce an expression, they may combine words that 
do not normally go together. For example, it is quite possible to say an obedient child or an obedient servant; learners in the present study, however, also perceived law-obedient people as a frequent English expression.

The ability to sound idiomatic (achieving 'nativelike selection,' in the words of Pawley \& Syder, 1983) is something that most advanced learners strive for, in their pursuit of second language proficiency, but few achieve to a native-like level. Pawley and Syder argue that many L2 learners produce grammatical sentences that are simply not used by native speakers. Native speakers typically use conventional phraseology to express meaning, while learners often express meaning with unconventional combinations of words. These unexpected combinations can be perceived as foreign and odd, making the learners less effective communicators and hindering their acceptance into the speech community.

While the fact that learners often have problems with collocation is well documented, the nature of this shortcoming is less so. This article reports on a series of three studies exploring this issue of learner collocation behaviour.

\section{Studies of learner collocation}

Research has established that learners often have problems with collocation. For example, Bahns and Eldaw (1993) tested advanced EFL learners' productive knowledge of 15 verb + noun collocations (e.g., serve a sentence) in a written translation task and a cloze test. They discovered that although collocations made up around 23\% of all lexical words (i.e., words belonging to open-class categories, thus excluding prepositions, articles, etc.), they accounted for more than $48 \%$ of all errors. Bahns and Eldaw thus suggest that collocations present a major problem for advanced learners because collocational competence does not develop in parallel with general vocabulary knowledge.

Howarth (1998) researched verb-object collocations extracted from native and non-native written corpora. He reports that NSs employed about $50 \%$ more restricted collocations (e.g., reach a conclusion) than advanced NNSs. Interestingly, he found deviation from standard collocational forms in both native and non-native writing; a much greater proportion of non-idiomatic language, however, was discovered in non-native essays. Specifically, non-standard collocations accounted for around $6 \%$ of collocations produced by learners and only $1 \%$ of native-speaker collocations. Howarth's findings also 
suggest that out of the three collocational groups - restricted collocations, free collocations, and idioms - learners seem to experience most difficulties in producing restricted collocations.

Other studies have also explored the nature of learner collocation problems. Nesselhauf (2003) explored the use of verb-noun collocations such as take a break and shake one's head in essays written by advanced German-speaking learners of English. Borrowing from Howarth (1998), Nesselhauf (2003) distinguishes three major classes of collocations: free combinations, such as want a car (both the verb and the noun are used in an unrestricted sense; words can be freely combined); collocations, such as take a picture (the sense of the noun is unrestricted, but that of the verb is restricted; one can also say take a photograph); and idioms, for example, sweeten the pill (both the verb and the noun are used in a restricted sense; substitution is not possible, or is very limited). The learners made the greatest proportion of errors with collocations (79\%), followed by free combinations (23\%) and idioms (23\%). However, Nesselhauf also found the highest rate of errors $(33 \%)$ in collocations with a medium degree of restriction (e.g., exert influence, where a number of other nouns such as control, pressure, and power are also possible) and a much lower rate (18\%) in collocations with 'a lot of restriction' (e.g., fail an exam/test, where fewer nouns are possible). These findings are congruent with those reported by Howarth.

Granger (1998) also investigated native and non-native knowledge of collocations, focusing on -ly intensifier + adjective collocations extracted from academic learner essays (L1 French) and essays written by native-English-speaking students. Granger distinguishes between two types of intensifiers: 'maximizers' (e.g., absolutely, totally) and 'boosters' (e.g., deeply, highly). She reports that the advanced learners' usage of the former was not different from the native usage; the 'boosters,' however, seem to be used with lower frequencies in learner production than in that of NSs. Having further submitted a number of -ly intensifier + adjective collocations to native and non-native (L1 French) informants, she reports that learners had a poorer sense of salience for collocations. Specifically, these learners were shown to be more accepting of combinations found unacceptable by the NSs. Overall, Granger concludes that although her learners did use collocations, they underused native-like expressions and tended to use atypical word combinations instead.

In yet another study, Farghal and Obiedat (1995) tested Arabic EFL students for the productive knowledge of 11 adjective + noun and noun + noun English collocations (e.g., weak tea, depth of winter) 
in two written tasks. They conclude that, overall, L2 learners could not cope with collocations because they were not made aware of collocations in the language. They suggest that this led students to employ strategies of 'lexical simplification' such as synonymy, paraphrasing, avoidance, and transfer, as well as to use literal translation from their L1.

Research into learners' collocational knowledge has basically used two types of methodology. Analyses of collocations extracted from learner corpora have explored learner production (e.g., Granger, 1998; Howarth, 1998; Nesselhauf, 2003, 2004), while the use of various types of questionnaires, interviews, and tests (e.g., Bahns \& Eldaw, 1993; Biskup, 1992; Farghal \& Obiedat, 1995) has yielded insights into how and why certain target collocations are used. The latter type of task is 'off-line,' in the sense that (a) there are no time constraints and (b) the results obtained do not reflect the immediate cognitive processes involved. Another methodological possibility exists, however. Marinis (2003) points out that very little is known about the way learners process an L2 in real time and highlights the benefits of using 'online' experimental methodologies in SLA research. These methodologies presuppose that (a) the task is performed under time pressure and (b) the results are believed to reflect cognitive processes involved in reading or listening to target words, word combinations, or whole sentences.

Such online tasks have been widely employed in exploring L1 processing of idioms. For example, Gibbs, Bogdanovich, Sykes, and Barr (1997) show that idiomatic expressions in story contexts (He blew his stack) are processed just as quickly as their literal paraphrases (He got very angry) but faster than control phrases (He saw many dents). However, online tasks are just beginning to be used in the study of L2 formulaic language. Underwood, Schmitt, and Galpin (2004) used an eye-movement technique to demonstrate that the terminal words in formulaic sequences were read with fewer eye fixations (by both NS and NNS participants) and more quickly (by NS participants only) than the same words in non-formulaic contexts. Similarly, Conklin and Schmitt (in press) found that formulaic sequences were read more quickly than non-formulaic equivalents in a self-paced reading experiment.

Because SLA issues are so complex, it is always useful to explore them from different perspectives and triangulate the results. Therefore, we employed a multiple-study approach in our investigation of L2 collocation behaviour. The three studies used corpus evidence, an off-line judgement task, and an online reaction-time task 
to seek answers to the following questions concerning L2 mastery of adjective-noun collocations:

- Study 1: Do L2 learners produce a large number of appropriate collocations in their writing?

- Study 2: How do NNSs compare against NSs in their judgements of frequent, less frequent, and infrequent collocations? Does L2 natural exposure contribute to a more native-like collocational competence?

- Study 3: How do NNSs differ from NSs in their reaction times when reading and processing adjective-noun collocations online?

Study 1 used a purely corpus-based approach to investigate learner production of adjective-noun collocations. Study 1 results are also of methodological value for Studies 2 and 3: several collocations identified in Study 1 served as target sequences for the subsequent studies. Studies 2 and 3 both addressed the level of learner collocational awareness, Study 2 in terms of accuracy of intuition and Study 3 in terms of automaticity.

\section{Study 1: Learner Collocations in L2 Writing}

The first study explores learner adjective-noun collocations by (a) using a corpus approach using frequency/association strength criteria and (b) comparing NNS data with NS data.

\section{Methodology}

The learner corpus

The data source used was part of the Russian sub-corpus of the International Corpus of Learner English (ICLE), a corpus of 2,500,353 words (Granger, Dagneaux, \& Meunier, 2002) consisting of essays written by 31 Russian university students from Moscow Lomonosov State University $(\approx 24,500$ words $)$ who were studying English as a foreign language at an advanced level. The students (6 male, 25 female) ranged in age from 19 to 36 years and had been studying English for six to 12 years. Only four had spent some time (two weeks to two months) in an English-speaking country. 
The native corpus

The Louvain Corpus of Native English Essays (LOCNESS), containing 324,304 words (Granger, Sanders, \& Connor, n.d.), was compiled to be the native equivalent of the ICLE corpus. It consists of essays from native English-speaking university students. To make the data from the ICLE and LOCNESS as comparable as possible in our study, we used 22 argumentative essays $(\approx 25,000$ words) written by nativeEnglish-speaking students at Marquette University. The age range of these students was 18-21 years; gender distribution is unknown.

\section{Procedure}

For this study, 810 adjacent adjective-noun collocations (e.g., long time) were manually extracted from the Russian sub-corpus and 806 adjective-noun combinations from the native essays. We consulted the British National Corpus (BNC), which contains $\approx 100$ million words, to determine the frequency and mutual information (MI) of each NNS and NS collocation. Using the BNC frequency information, we split the collocations into five frequency bands: 0 (failed to appear in the BNC), 1-5, 6-20, 21-100, and $>100$ occurrences. MI is a standard measure used to show how strongly associated the words are and how likely it is that they will co-occur. For example, the combination extenuating circumstances will have a very high MI score, because whenever we read or hear extenuating, we are extremely likely to see or hear circumstances after it; the expression red car will have a much lower MI score, since many things can be red, and cars in general can be of different colours. MI therefore is particularly good at discovering 'interesting collocations' (Manning \& Schütze, 1999), as it is not so strongly linked with frequency as other association measures. MI delivers a score ranging from around zero to somewhere around 17; the higher the score, the more strongly associated the words are. According to Hunston (2002), an MI score of 3 or above is often taken to indicate a significant collocation threshold.

The BNC is the best corpus of general English currently freely accessible to researchers. There are larger corpora in existence (e.g., the COBUILD Bank of English corpus), but the BNC has the advantage of being balanced across various genres of English, and so is the most representative corpus of general English available. We do not know whether the Russian learners were exposed to British or American English at their home university, but, regardless, the BNC was still the best choice for norming their output, especially as the American 
English counterpart of the BNC is still in the process of being compiled.

\section{Results and discussion}

Corpus analysis - NNS data

The main research question for this study concerns the appropriateness of learner adjective-noun combinations. One way of determining appropriateness is by looking at whether the same combinations occur frequently in a native corpus. If so, the assumption is that they are native-like collocations.

As can be seen from Figure 1, 51.5\% of the 810 L2 adjective-noun combinations occurred relatively frequently ( $\geq 6$ occurrences) in the BNC. Thus, based on frequency alone, about half the L2 collocations in the 31 essays taken from the Russian learner sub-corpus can be considered typical of native production. Conversely, one-quarter of the combinations did not appear in the BNC at all. About another quarter of the 810 combinations have a low frequency (between 1 and 5 occurrences as attested in the BNC). Thus, the frequency information indicates that around half $(48.5 \%)$ of all combinations extracted from learner essays are either atypical or, at least, infrequent in the BNC.

Another way to view collocations is in terms of their association strength. Although it is possible to calculate MI scores for all

FIGURE 1

Distribution of NNS collocations on the basis of their BNC frequency $(N=810)$.

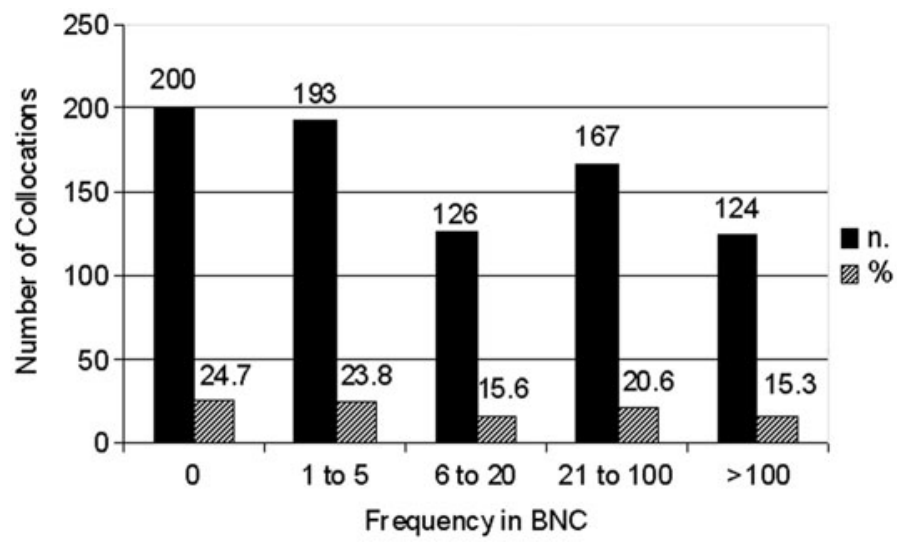

(C) 2008 The Canadian Modern Language Review/La Revue canadienne des langues vivantes, 64, 3 (March/mars), 429-458 
TABLE 1

NNS collocations with a BNC frequency of $\geq 6$ and $\mathrm{Ml}$ of $\geq 3$

\begin{tabular}{lll}
\hline & $\mathrm{Ml} \geq 3$ & Total learner \\
& $\mathrm{FR} \geq 6$ & collocations \\
\hline$N$ & 361 & 810 \\
$\%$ & 44.6 & 100 \\
\hline
\end{tabular}

collocations with a frequency above 0, many researchers (Evert \& Krenn, 2001; Manning \& Schütze, 1999; Xiao \& McEnery, 2006) point out that the lowest-frequency data are a serious challenge for MI. Therefore, following Evert and Krenn, we decided to adopt a frequency threshold in addition to Hunston's (2002) MI threshold of 3 . We selected a frequency figure of 6 , because it is the lowest figure in our top three frequency categories and is low enough to include nearly half the data. Of all learner combinations, we find that around $45 \%$ $(361 / 810)$ meet the native-like threshold of frequency of $\geq 6$ and MI threshold of $\geq 3$, according to BNC norms (see Table 1).

The corpus analyses indicate that a large percentage of the learners' collocations could be considered appropriate, that is, frequent and strongly associated English word combinations. While $24.7 \%$ of their combinations did not occur in the BNC, $75.3 \%$ were attested at least once. Furthermore, the MI analysis showed that $44.6 \%$ of the collocations occurred at least six times in the BNC and achieved the significant collocation threshold level of 3 . This means that, based on joint frequency/MI criteria, close to half of adjective-noun combinations produced in the 31 learner essays were appropriate collocations. It is worth noting at this point that these findings do not indicate that the remaining $55.4 \%$ were inappropriate or wrong. In a separate analysis not reported here, we found evidence that many of these were in fact appropriate as well. Based on the criteria set out in Study 1, we can be confident that at least $44.6 \%$ of the collocations produced were native-like and appropriate; but the figure of $44.6 \%$, in isolation, does not tell us much about learner collocational knowledge. Is it a nativelike proportion of appropriate collocations? Or is it well below what we would expect of NSs? One way to answer this question is to look at comparable NS data.

Corpus analysis - NS data

Figure 2 shows that the distribution of NS collocations on the basis of their frequency is surprisingly similar to the NNS distribution. 
FIGURE 2

Distribution of NS collocations on the basis of their BNC frequency $(N=806)$.

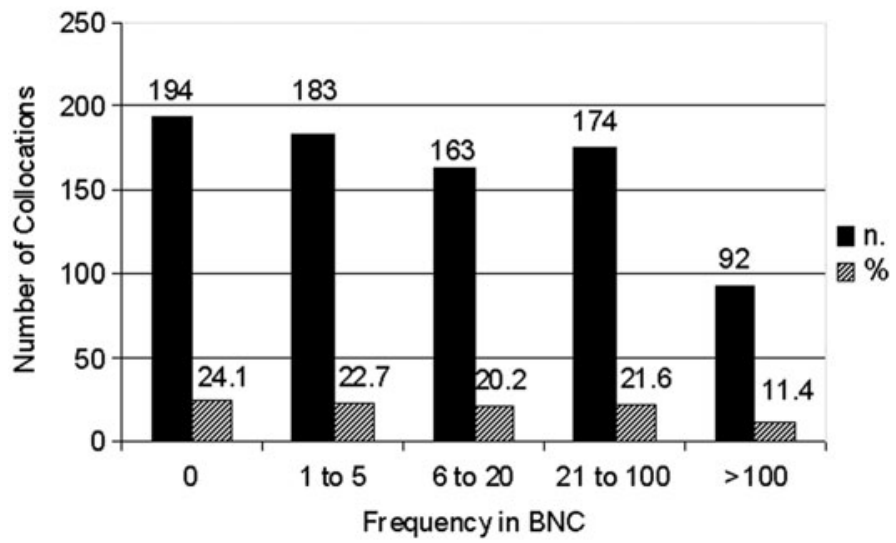

TABLE 2

NS collocations with a BNC frequency of $\geq 6$ and $\mathrm{Ml}$ of $\geq 3$

\begin{tabular}{lll}
\hline & $\mathrm{Ml} \geq 3$ & Total NS \\
& $\mathrm{FR} \geq 6$ & collocations \\
\hline$N$ & 388 & 806 \\
$\%$ & 48.1 & 100 \\
\hline
\end{tabular}

That is, about one-half (53.2\%) of the 806 NS adjective-noun combinations occurred relatively frequently ( $\geq 6$ occurrences) in the BNC. Likewise, one-quarter of all NS combinations failed to appear in the $\mathrm{BNC}$, and just under one-quarter appeared at very low frequencies (i.e., 1-5 occurrences). These figures are nearly identical to those of the learners. Overall, it seems that the NNSs are producing adjectivenoun combinations that are of similar frequencies to those produced by NSs. These results are strengthened by the fact that the two corpora are highly comparable in terms of genre (argumentative essays), size $(\approx 25,000$ words), and the total number of adjective-noun combinations extracted ( 810 vs. 806 ).

With the frequency information in hand, we then added the information on strength of association (MI). Table 2 shows that around $48 \%$ of all NS pairings meet our criteria of a typical collocation, that is, having a frequency of at least 6 and an MI score of at least 3 . 
Having obtained the proportions of appropriate collocations in NS and NNS essays, we can now calculate whether or not the difference between the two figures is statistically significant. The chi-square test shows no significant difference between native speakers and learners in the proportion of typical collocations produced: $\chi^{2}(1, N=1616)=2.07, p>0.05$. This reflects the fact that based on the odds ratio (0.87), the NSs were not more likely than the NNSs to produce a greater number of appropriate collocations in their essays.

Study 1 demonstrates that about half of the adjective-noun combinations produced by the NS university students were essentially phrasal in nature (i.e., relatively frequent, strongly associated collocations), while the other half were more creative, in the sense that they were not typical collocations as attested by BNC data. This mixture is not surprising, as native speakers can be expected to use both idiom and open-choice principles (Sinclair, 1991) in their language production. The ratio of phrasal versus creative language is more interesting, and our 50/50 split is similar to Erman and Warren's (2000) findings that 52.3\% of written English discourse is formulaic in nature. The Russian university students whose essays form the NNS corpus for Study 1 produced collocations in similar frequencies to the native students, and so can be considered quite successful in their production of adjective-noun collocations. Thus, the evidence obtained in this study does not support a commonly held view that L2 learners underuse native-like collocations (as argued by Granger, 1998, for example). As our corpus analyses have shown, these learners were as likely as a comparable group of native speakers to produce frequent and strongly associated collocations in their essays.

\section{Study 2: Comparing native and non-native judgements of collocation}

Study 1 demonstrated that the Russian students were quite successful at producing appropriate adjective-noun collocations. The study thus suggests that L2 learners in general are capable of considerable collocational knowledge. However, we can explore collocational knowledge from another perspective, that is, the mental processing underlying that production. This normally requires experimental designs that directly measure language competences and intuitions. Study 2 used such a design to explore native and non-native judgements of native-like versus atypical collocations and to 
investigate whether L2 natural exposure has any beneficial effect on non-native collocational knowledge.

\section{Methodology}

\section{Instrument}

The first step in the study was to design a measure that could be given to participants to elicit their knowledge of collocation. We wanted to use collocation targets that had some chance of being familiar to our L2 participants, so we drew from the 810 adjective-noun collocations collected for Study 1. As we found that the Russian learners in the ICLE sub-corpus produced some collocations that were frequent and others that were infrequent, we decided to examine both categories of collocations. Since the frequent collocations needed to be unambiguously appropriate, they were chosen on the basis of frequency (BNC frequency $\geq 21$ ), association strength $(\mathrm{MI} \geq 3)$, and inclusion in two well-known collocation references, The BBI Dictionary of English Word Combinations (BBI; Benson, Benson, \& Ilson, 1997) and the Oxford Collocations Dictionary (OCD, 2002). We originally selected 35 frequent and 35 infrequent collocations, but when it became clear that many respondents did not know some of the constituent words in several of the collocations, we had to exclude these; we ended up with 31 frequent and 31 infrequent collocations. Although a few of the collocations did not meet all four criteria, the balance of the evidence indicates that the 31 frequent collocations on the measure are indeed both frequent and typical of native usage (see Table 3). From the 31 frequent collocations we also extracted two sub-groups of 10 collocations, each based on frequency: (a) collocations with a BNC frequency of over 100 (hereafter 'high-frequency collocations') and (b) collocations with a BNC frequency of 21 to 100 ('mediumfrequency collocations'). The collocations in these two frequency groups were matched for length.

The 31 infrequent collocations (see Table 4) were chosen on the basis of their non-occurrence in the BNC; moreover, none of the infrequent collocations occurred in the BBI or OCD. In addition, their constituent parts had to be meaningful and grammatically correct English words. For example, in law-obedient people, although one of the words (law-obedient) does not exist in English, both law and obedient do exist, and thus the meaning of law-obedient people should be quite transparent, even though the collocation itself is atypical of English. 
TABLE 3

31 frequent adjective-noun target collocations*

\begin{tabular}{|c|c|c|c|c|c|}
\hline & Adjective-noun collocation & Frequency & Ml & $\mathrm{BBI}$ & OCD \\
\hline 1 & ancient times & 73 & 5.7 & yes & yes \\
\hline 2 & characteristic feature & 49 & 10.3 & yes & yes \\
\hline 3 & common people & 109 & 2.2 & yes & yes \\
\hline 4 & criminal offence & 207 & 11.1 & yes & yes \\
\hline 5 & favourable conditions & 43 & 7.5 & yes & yes \\
\hline 6 & full-time employment & 92 & 8.8 & yes & yes \\
\hline 7 & great deal & 4025 & 10.2 & yes & no \\
\hline 8 & helping hand & 121 & 11.4 & yes & no \\
\hline 9 & human rights & 2316 & 10.5 & yes & yes \\
\hline 10 & human society & 141 & 5.6 & no & yes \\
\hline 11 & individual approach & 21 & 3.7 & no & no \\
\hline 12 & individual circumstances & 44 & 5.2 & no & no \\
\hline 13 & juvenile delinquency & 34 & 15.8 & yes & no \\
\hline 14 & living conditions & 192 & 10.6 & yes & yes \\
\hline 15 & military service & 277 & 6.5 & yes & yes \\
\hline 16 & mitigating circumstances & 24 & 12.5 & yes & yes \\
\hline 17 & moral principles & 52 & 7.5 & yes & no \\
\hline 18 & ordinary life & 100 & 4.7 & no & yes \\
\hline 19 & physical disabilities & 61 & 9.8 & yes & yes \\
\hline 20 & primary importance & 44 & 6.3 & yes & yes \\
\hline 21 & primary interest & 25 & 4.1 & no & no \\
\hline 22 & prime example & 127 & 6.3 & yes & yes \\
\hline 23 & public order & 409 & 7.1 & yes & yes \\
\hline 24 & right mind & 74 & 4.1 & yes & no \\
\hline 25 & senior official & 71 & 9.2 & yes & yes \\
\hline 26 & single-parent families & 53 & 13.2 & yes & yes \\
\hline 27 & social stability & 42 & 5.5 & no & yes \\
\hline 28 & vast majority & 859 & 10.8 & yes & yes \\
\hline 29 & vicious circle & 127 & 12.2 & yes & no \\
\hline 30 & social services & 2285 & 7.7 & yes & yes \\
\hline 31 & vital importance & 111 & 7.8 & yes & yes \\
\hline
\end{tabular}

Boldface type indicates cases where a selection criterion was not met.

The 31 frequent and 31 infrequent collocations were combined, in random order, and attached to the collocation instrument. Participants were asked to rate all 62 collocations on the basis of their commonness in the English language. Although we were interested in judgements about the acceptability of the collocations, collocations that are used 
frequently by natives are clearly acceptable, while collocations that do not occur in 100 million words are much less likely to be so. We felt that a judgement task relating to frequency would be more transparent to our participants than a task asking them to rate acceptability. Therefore, the instructions required the participants to rate the

\section{TABLE 4}

31 infrequent adjective-noun target collocations (do not occur in $\mathrm{BNC}, \mathrm{BBI}$, or $\mathrm{OCD}$ )

\begin{tabular}{|c|c|}
\hline & Adjective-noun collocation \\
\hline 1 & plastic operation \\
\hline 2 & permanent horror \\
\hline 3 & simple violators \\
\hline 4 & educative people \\
\hline 5 & abnormal organisation \\
\hline 6 & exclusive crimes \\
\hline 7 & disputable questions \\
\hline 8 & bitter prisoner \\
\hline 9 & excellent society \\
\hline 10 & civilised prisons \\
\hline 11 & full-valued members \\
\hline 12 & criminal relatives \\
\hline 13 & law-obedient people \\
\hline 14 & ill atmosphere \\
\hline 15 & cynical murderers \\
\hline 16 & exhausted cripples \\
\hline 17 & inner protest \\
\hline 18 & grown-up criminal \\
\hline 19 & synonymous answer \\
\hline 20 & unclaimed person \\
\hline 21 & conditioned punishment \\
\hline 22 & drying-out clinics \\
\hline 23 & elementary conveniences \\
\hline 24 & inborn ideas \\
\hline 25 & inborn principles \\
\hline 26 & unmoral behaviour \\
\hline 27 & voluntary accomplices \\
\hline 28 & skilful specialists \\
\hline 29 & vicious situation \\
\hline 30 & life-long outcasts \\
\hline 31 & intent attention \\
\hline
\end{tabular}

(C) 2008 The Canadian Modern Language Review/La Revue canadienne des langues vivantes, 64, 3 (March/mars), 429-458 
collocations according to frequency on a six-point scale. We used the lay term common for the notion of frequency, so the scale had the following descriptors: 1 (very uncommon), 2 (uncommon), 3 (fairly uncommon), 4 (fairly common), 5 (common), and 6 (very common).

\section{Participants}

A total of 120 participants took part in the study: 60 native and 60 non-native speakers of English. All native speakers were students at the University of Nottingham or at Nottingham Trent University (44), professionals (10), or members of staff at the University of Nottingham (6). Non-native participants, a mixture of advanced ESL and EFL learners, were undergraduate or postgraduate students at the University of Nottingham (23) or professionals (37) (mainly English teachers, translators, managers, or administrators), in the United Kingdom and elsewhere, who majored in English in their home countries and who work with English on a regular basis. The age range of all participants was between 18 and 54 years old; 51 participants were male and 69 female. The L1s of the NNS participants can be found in Table 5. All participants were unpaid volunteers.

In order to measure the role of L2 natural exposure, all NNS participants were split into three groups according to how long they had visited or lived in an L2 country:

- never been to an L2 country - 29 participants

- 12 months or less -17 participants (average stay $=8.4$ months)

- more than 12 months -14 participants (average stay $=4.5$ years)

TABLE 5

Native languages of 60 NNS participants in Study 2

\begin{tabular}{lr}
\hline L1 & $N$ \\
\hline German & 1 \\
Dutch & 2 \\
Greek & 4 \\
Chinese & 9 \\
Icelandic & 1 \\
Thai & 7 \\
Russian & 15 \\
Polish & 1 \\
Vietnamese & 20 \\
\hline
\end{tabular}

(C) 2008 The Canadian Modern Language Review/La Revue canadienne des langues vivantes, 64, 3 (March/mars), 429-458 


\section{Procedure}

The test was administered to the 120 participants either via e-mail, or in person at the University of Nottingham library. Participants were told that the aim of the study was to investigate the intuitions of native and non-native speakers of English. We feel confident that NNS participants did not consult any sources when doing the test because (a) they were explicitly asked not to consult anything or anyone, (b) we personally administered the test to half of the NNS participants and controlled for this, and (c) those participants who were tested via e-mail had the most inaccurate scores, and so it is unlikely that they consulted sources. In the analysis, all data were found to deviate from normality; hence, non-parametric tests were used.

\section{Results and discussion}

The main purpose of the study was to determine how well the L2 participants could distinguish between frequent (i.e., native-like) and infrequent (i.e., atypical) collocations, with native performance as a baseline (henceforth, the terms "frequent" and "native-like," and the terms "infrequent" and "atypical," will be used interchangeably). Table 6 shows that NNS participants rated the native-like collocations as far less frequent than the NS participants did. Similarly, the NNSs rated the atypical collocations as more frequent than the NS participants did. The differences are statistically reliable, according to Mann-Whitney $U$-tests (native-like: $U=378, p<0.001$; atypical: $U=535.50, p<0.001)$. The NS participants had good intuitions about the frequent collocations, rating them near the maximum end of the scale. The NNSs clearly had poorer intuitions about the frequent collocations, as their median ratings are a full point lower.

TABLE 6

Native and non-native judgements of collocations

\begin{tabular}{llll}
\hline & $\begin{array}{l}\text { Native-like / frequent } \\
\text { collocations (Median*) }\end{array}$ & $\begin{array}{l}\text { Atypical / infrequent } \\
\text { Collocations (Median*) }\end{array}$ & $p^{* *}$ \\
\hline NS & 5.50 & 2.51 & 0.001 \\
NNS & 4.51 & 3.32 & 0.001 \\
$p^{* * *}$ & 0.001 & 0.001 & \\
\hline$* 1$ =very uncommon, $6=$ very common & & \\
$* *$ Wilcoxon signed ranks test & & \\
$* * *$ & Mann-Whitney $U$-test
\end{tabular}

(C) 2008 The Canadian Modern Language Review/La Revue canadienne des langues vivantes, 64, 3 (March/mars), 429-458 
It should be noted, however, that the NNSs did rate the frequent collocations on the higher half of the scale, which indicates emerging collocation knowledge; their knowledge was just not as accurate as that of the NSs.

The NS participants rated the infrequent collocations at the lower end of the scale, which shows that they had reliable intuitions that the collocations are not in common use. However, they did not rate the atypical collocations near the extreme end of the scale, as they did with the frequent collocations. This may be because NSs are tolerant of unusual collocations as long as they make sense. The NNS participants rated the atypical collocations near the middle of the scale, indicating that they did not have strong intuitions that these collocations are unusual. Overall, the NNSs tended to underestimate the frequency of common collocations and overestimate the frequency of uncommon ones.

We can also get an idea of the accuracy of participants' collocation intuitions by correlating their rating responses with the BNC frequency data. The NSs showed a stronger correlation (Spearman, $r=0.578, \quad p \quad$ (one-tailed) $<0.01) \quad$ than the NNSs $(r=0.440, \quad p$ (one-tailed) $<0.01$ ).

Unsurprisingly, the NS ratings of frequent versus atypical collocations were significantly different from each other (Wilcoxon signed ranks, $T=0, p<0.001)$. However, even though the NNSs made relatively poor judgements compared to the NSs, their ratings of frequent versus atypical collocations were also significantly different $(T=93.50, p<0.001)$. This shows that they did have intuitions that the two collocation groups were different; their ratings were simply not as accurate as those of the NSs.

One might argue, however, that the above results are unsurprising, since the collocations in question represent two extremes: very frequent and very infrequent. To compare judgements of collocations with closer frequencies, we examined the 10 'high-frequency' collocations (BNC > 100) and the 10 'medium-frequency' collocations $(B N C=21-100) \quad$ (see Table 7). The NS participants reliably differentiated between these high- and medium-frequency collocations (Wilcoxon signed ranks, $T=195, p<0.001$ ), but the NNSs did not ( $T=708, p>0.05$; see Table 8 for medians). This finding illustrates that NSs not only have good intuitions of what collocations are very frequent and very infrequent in language but can also distinguish finer shades of frequency. In contrast, while the NNSs could distinguish between collocations of extreme frequency difference, they had not yet developed finer-grained intuitions that 
TABLE 7

Medium- and high-frequency collocations

\begin{tabular}{|c|c|c|c|c|c|c|c|}
\hline & $\begin{array}{l}\text { Medium Frequency } \\
(21-100)\end{array}$ & Frequency & Ml & & $\begin{array}{l}\text { High Frequency } \\
(>100)\end{array}$ & Frequency & Ml \\
\hline 1 & ancient times & 73 & 5.7 & 1 & common people & 109 & 2.2 \\
\hline 2 & individual approach & 21 & 3.7 & 2 & criminal offence & 207 & 11.1 \\
\hline 3 & moral principles & 52 & 7.5 & 3 & human society & 141 & 5.6 \\
\hline 4 & primary importance & 44 & 6.3 & 4 & living conditions & 192 & 10.6 \\
\hline 5 & primary interest & 25 & 4.0 & 5 & military service & 277 & 6.5 \\
\hline 6 & right mind & 74 & 4.1 & 6 & prime example & 127 & 6.3 \\
\hline 7 & senior official & 71 & 9.2 & 7 & vast majority & 859 & 10.8 \\
\hline 8 & social stability & 42 & 5.5 & 8 & vicious circle & 127 & 12.2 \\
\hline 9 & ordinary life & 100 & 4.7 & 9 & social services & 2,285 & 7.7 \\
\hline 10 & full-time employment & 92 & 8.8 & 10 & vital importance & 111 & 7.8 \\
\hline
\end{tabular}

TABLE 8

Judgements of medium- and high-frequency collocations

\begin{tabular}{lllll}
\hline & NS & & NNS & \\
& Median* & $\mathrm{p}^{* *}$ & Median* & $\mathrm{p}^{* *}$ \\
\hline Medium frequency & 5.20 & 0.001 & 4.50 & 0.345 \\
High frequency & 5.50 & & 4.65 & \\
\hline
\end{tabular}

$1=$ very uncommon, $6=$ very common

* Wilcoxon signed ranks test

would enable them to differentiate between medium- and highfrequency collocations.

These results are also supported by Spearman's correlation tests, which revealed strong positive correlations between NS participants' responses and BNC frequency with respect to both medium-frequency $(r=0.742, \quad p \quad$ (one-tailed $)<0.01) \quad$ and high-frequency $\quad(r=0.707$, $p$ (one-tailed) $<0.05$ ) collocations. Conversely, the NNS ratings had no significant correlation with BNC frequency for either medium- or high-frequency collocations (both $p$ (one-tailed) $>0.05$ ).

\section{L2 natural exposure and collocational competence}

A second goal of this study was to explore the influence of L2 natural exposure on learner collocational competence. It has been suggested that successful acquisition of prefabricated language requires 
TABLE 9

The effects of $L 2$ natural exposure on collocation knowledge

\begin{tabular}{llll}
\hline Collocation & $\begin{array}{l}\text { No exposure vs. }<12 \\
\text { months }\end{array}$ & $\begin{array}{l}\text { Length of stay } \\
\text { No exposure vs. }>12 \\
\text { months }\end{array}$ & $\begin{array}{l}<12 \text { months vs. } \\
>12 \\
\text { months }\end{array}$ \\
\hline Native-like / frequent & $0.001^{*}$ & $0.001^{*}$ & 0.200 \\
Atypical / infrequent & 0.050 & $0.007^{*}$ & 0.653 \\
\hline
\end{tabular}

* Kruskal-Wallis test with Mann-Whitney post-hoc, $p<0167$ (Bonferroni correction)

prolonged L2 natural exposure (Adolphs \& Durow, 2004; Dörnyei, Durow, \& Zahran, 2004). Some have gone as far as to suggest that L2 natural exposure is so important that language acquisition in an L2 environment leads to native-like proficiency while language acquisition in a classroom setting does not (Schinke-Llano, 1990). Although this claim seems excessive, our findings do suggest that extended stays in an L2-speaking environment lead to a more nativelike idiomaticity. Interestingly, several studies, such as that of Yorio (1989), provide rather different results. Yorio compared the idiomatic performance of a group of immigrants who were studying English in an L2 environment with that of a group of EFL learners who had had only classroom-based tuition. He found that the EFL group made more use of idiomatic expressions than the immigrant group and that their written English seemed more natural and authentic. However, as Dörnyei et al. point out, success in acquiring idiomatic language is related to learners' involvement in the life of the local community; immigrant groups often resist too-close contact with the locals and prefer to stay in their small communities, speaking mostly their L1. Other studies - Segalowitz and Freed (2004), for example - have investigated the role of learning context in oral performance. Segalowitz and Freed found that learners in the study-abroad context made greater gains in oral performance than learners in the home-university context; they also admit, however, that 'the picture as a whole is complex' (p. 192). Segalowitz and Freed rightly point out that learning contexts differ in terms of the opportunities they present to language learners, who, in turn, differ in their linguistic and cognitive readiness to seize these opportunities.

Table 9 shows that ratings of native-like/frequent collocations by the ' 12 months or less' group and the 'over 12 months' group were significantly different from the ratings of the 'no exposure' group. On the other hand, when the ' 12 months or less' group was compared 
to the 'over 12 months' group, no significant differences were found. There was a significant trend in the overall data, however: as more time was spent in an English-speaking environment, the median for common collocations increased (Jonckheere's test, $J=900, z=4.59$, $r=0.59$ ). A somewhat different picture emerges for the atypical/ infrequent collocations, for which only the 'no exposure' group and the 'over 12 months' group differ significantly in their collocation ratings. Again, however, there was the same trend in the overall data $(J=367, z=-2.79, r=-0.36)$.

This finding provides evidence that more L2 exposure does lead to better intuitions about collocations. A prolonged stay in an Englishspeaking country, whether it is shorter than 12 or longer than 12 months, can enable learners to become more native-like in their judgements of frequent collocations than learners without any L2 natural exposure. However, it seems to take more than 12 months to start developing better intuitions about which word combinations are, in fact, atypical and infrequent. It may be that acquiring frequent collocations in an L2 environment takes less time than developing feelings for what is atypical in a language.

It is noteworthy that although extended stays did make a significant difference in the NNS scores, this difference was not large enough to bridge the gap between the NSs and NNSs. Specifically, the scores for frequent collocations of those L2 learners who had spent more than 12 months in an English-speaking country (Median = 5.10) were still lower than those of the NS participants (Median=5.50), $U=211$, $p<0.005$. Likewise, the scores for atypical collocations of the 'over 12 months' group (Median $=2.98$ ) were significantly higher than those of the NSs (Median =2.51), $U=201, p<0.005$.

We also examined whether L2 exposure affected the more nuanced intuitions necessary to distinguish between medium- and highfrequency collocations. When all NNSs were grouped together, they did not rate these collocations differently (see above). While this was still true for the 'no exposure' and the ' 12 months or less' groups, the 'over 12 months' group was able to differentiate between the collocations (see Table 10).

On the basis of all of the above findings, it seems reasonable to suggest that English language learners who have been exposed to naturally occurring English are better able to distinguish between native-like collocations and atypical collocations, although it may take 12 months or more of exposure for them to become sensitive to the nuances of collocations that are native-like but merely have a slightly higher or slightly lower frequency. 
TABLE 10

The effects of L2 natural exposure on judgements of medium- and high-frequency collocations

\begin{tabular}{|c|c|c|c|c|c|c|}
\hline \multirow[t]{2}{*}{ Collocation frequency } & \multicolumn{2}{|c|}{ No exposure } & \multicolumn{2}{|c|}{$<12$ months or less } & \multicolumn{2}{|l|}{$>12$} \\
\hline & Median* & $p^{* *}$ & Median* & $p^{* *}$ & Median & $p^{* *}$ \\
\hline \multirow[t]{2}{*}{ Medium } & 3.90 & & 4.70 & & 5.05 & \\
\hline & & 0.965 & & 0.909 & & 0.014 \\
\hline High & 3.70 & & 4.80 & & 5.20 & \\
\hline
\end{tabular}

$1=$ very uncommon, 6 = very common

** Wilcoxon signed ranks test

\section{Study 3: Speed of processing of collocation judgements}

Study 2 established that NNS judgements of collocation frequency were not as accurate as native judgements. This is one strand of evidence for the relative deficiency of NNS intuitions regarding collocation. Another way to approach this issue is to measure how quickly such judgements are made, that is, to use an online task to measure the fluency of collocation knowledge. In Study 3, therefore, we attempted to demonstrate the speed with which NSs and NNSs process collocations of different frequencies in real time.

\section{Methodology}

\section{Instrument}

In this study, the focus was on differences between NSs and NNSs in their recognition of the target collocations extracted from the ICLE. We use the term recognition in its broad sense, namely the process of (a) reading, (b) locating in the mental lexicon, and (c) making decisions. As we are concerned with recognition times in this study, it is important to control factors that are known to affect the speed of recognition. Many are related to the context in which a linguistic item is embedded, but, since this study presented collocations in isolation, two non-contextual factors are pertinent. The frequency of a word is a crucial factor in word-recognition tasks (Balota, 1994; Harley, 2001), and this is the variable manipulated in Study 3. Word length can also affect recognition times, and so the collocations in which frequency is an issue (the 10 high-frequency and 10 medium-frequency collocations from Study 2) had already been matched for word length in anticipation of this study. Thus, the instrument for Study 3 is the same as the one used in Study 2, consisting of 62 items: 31 native-like and 31 atypical collocations. 
As in Study 2, the participants were asked to rate the collocations on the basis of their frequency in the English language. In this case, however, the participants' reaction times rather than their actual responses were compared. A computer program was written specifically to measure the participants' reaction times using the collocation prompts. ${ }^{1}$

\section{Participants}

Fifty-four participants took part in the study: 27 native and 27 advanced non-native speakers of English. All NSs were students (24), recent graduates (2), or members of staff (1) at the University of Nottingham. The 27 NNS participants, all ESL learners, were undergraduate or postgraduate students at the University of Nottingham (25) or recent graduates residing in Nottingham (2). Participants ranged in age from 19 to 44 years old; 17 were male and 37 female. The NNS participants' L1 backgrounds are listed in Table 11. All participants were unpaid volunteers.

\section{Procedure}

The participants were asked to do the test in one of the University of Nottingham's computer labs, where they were tested individually. During the experiment, collocations were displayed on a computer screen in the same random order in which they appeared on the questionnaire in Study 2. Thus, participants could not anticipate

TABLE 11

Native languages of 27 NNSs in Study 3

\begin{tabular}{lc}
\hline L1 & $N$ \\
\hline Chinese & 13 \\
Bahasa (Indonesia) & 1 \\
Thai & 1 \\
German & 1 \\
Farsi & 1 \\
Hungarian & 1 \\
French & 1 \\
Turkish & 2 \\
Spanish & 4 \\
Arabic & 1 \\
Greek & 1 \\
\hline
\end{tabular}

(C) 2008 The Canadian Modern Language Review/La Revue canadienne des langues vivantes, 64, 3 (March/mars), 429-458 
whether a native-like or an atypical collocation would come up next on the screen. Participants were asked to rate each collocation in terms of its 'commonness,' in the same manner as in Study 2. There was no time limit for responding, and participants could take as long as they needed to make their judgement. That is, there was no preset limit (e.g., 2,000 or 3,000 ms) after which the screen would automatically change to the next item. Participants were told that the task would be timed and were also asked to complete the task as quickly as possible. The data were found to be normal, except where indicated below, and so parametric statistics were used when appropriate.

\section{Results and discussion}

Table 12 illustrates the mean time needed to make frequency judgements of the target collocations. All the comparisons proved to be significant. Paired samples $t$-tests showed that NSs judged both frequent and infrequent collocations more quickly than NNSs. Moreover, the difference in speed of judgement was very large in the terms of a psychological experiment: more than a full second. This result indicates that not only are NNS judgements of collocational frequency less accurate than those of NSs (Study 2) but that the recognition processing necessary to reach those judgements proceeds more slowly for NNSs. Together with the results from Study 2, these results give a picture of L2 collocational knowledge as both less accurate and slower than native speakers' knowledge.

It is also interesting to note the effect of frequency in the word judgements. Both NSs and NNSs judged the frequent collocations more quickly than the atypical ones. Thus, the NNSs behaved similarly to the NSs, but they were slower across the board. This suggests that L2 learners, like their NS counterparts, react much faster when they read something more common in the language

TABLE 12

NS versus NNS speed of collocation judgement (ms)

\begin{tabular}{llllll}
\hline & \multicolumn{2}{l}{ Native-like / frequent collocations } & \multicolumn{2}{l}{ Atypical / infrequent collocations } & $p^{*}$ \\
& $M(\mathrm{~ms})$ & $S D$ & $M(\mathrm{~ms})$ & $S D$ & \\
\hline NS & 1945 & 372.40 & 3023 & 787.38 & 0.001 \\
NNS & 2813 & 788.14 & 3904 & 1264.64 & 0.001 \\
$p^{* *}$ & 0.001 & & & \\
\hline$*$ & & & \\
$* *$
\end{tabular}

(C) 2008 The Canadian Modern Language Review/La Revue canadienne des langues vivantes, 64, 3 (March/mars), 429-458 
than when they read something that, even if makes sense, sounds odd. This type of frequency effect is pervasive with individual words (see Ellis, 2002, for a good overview of frequency effects), and this study indicates that it also holds for collocations (at least, for adjective-noun combinations), for both NSs and NNSs. ${ }^{2}$

We also examined how NSs and NNSs differed in their reaction times when reading and processing collocations with less obvious differences in their frequency, namely the 10 medium-frequency and 10 highfrequency collocations used in Study 2 (which were also controlled for word length). Since the reaction times in this part of the study were not normally distributed, Wilcoxon signed ranks tests were used to determine differences between the groups. The NS participants took significantly less time to read and process high-frequency collocations than to read and process medium-frequency ones (see Table 13), but there was no significant difference in processing speed for the NNSs. Thus, frequency-based processing enhancement seems to be in effect for NSs even when the differences in frequency are relatively small. NNSs, on the other hand, seem to gain a processing advantage only when the differences in frequency are relatively extreme.

Overall, we find that NNSs, unlike NSs, do not differentiate between medium- and high-frequency collocations, whether in an off-line rating test (Study 2) or in an online test that measures recognition times (Study 3).

A possible limitation of this study is that the reaction times generated by our custom software program may not be quite as accurate as those generated by a standard experimental software package, such as E-prime. However, given that the significant differences found in the data are very large, mainly on the order of $1,000 \mathrm{~ms}$, we feel justified in assuming that the results are real and that they would not have been substantially different if a commercially purchased experimental software package had been used.

TABLE 13

Native versus non-native speed of collocation judgement for high and medium frequency collocations (ms)

\begin{tabular}{lllll}
\hline Collocation frequency & NS & & NNS & \\
& Median $(\mathrm{ms})$ & $p^{*}$ & Median $(\mathrm{ms})$ & $p^{*}$ \\
\hline Medium & 1,873 & 0.001 & 2,687 & 0.648 \\
High & 1,736 & & 2,891 & \\
\hline
\end{tabular}

* Wilcoxon signed ranks test 


\section{General discussion and implications}

It is widely accepted that L2 learners face a considerable challenge in mastering L2 collocations. However, this does not mean that teachers should automatically assume that most learner collocations will be atypical of NS production. Study 1 found that around $45 \%$ of the adjective-noun combinations produced by the Russian university students in the ICLE were, in fact, appropriate collocations; the figure of $45 \%$ is very congruent with the NS production of collocations (48\%). It is difficult to know how far we can generalize these results to other L2 learners of a similar ability. Likewise, we do not know whether other types of learner collocation (e.g., verb-noun, verb-adverb) would be produced at a similar level. Regardless, the results do seem to suggest that L2 learners at this level can produce a high proportion of frequent recurrent collocations.

However, despite the rather optimistic findings of Study 1, we cannot assume that NNSs necessarily develop native-like intuitions of collocation. Study 2 revealed that while native speakers had accurate intuitions of collocation frequency (at least as indicated by the BNC), advanced language learners had relatively poor intuitions. Specifically, the NNSs tended to judge uncommon collocations as more common and plausible than they actually were and, conversely, did not adequately perceive the higher frequency of common collocations. The learners were also unable to distinguish between medium- and high-frequency collocations, something that native speakers were able to do. Study 3 added to the results of Study 2, showing that NNSs were slower than native speakers in judging collocations and that the learners did not have good enough intuitions to process the highfrequency collocations more quickly than the medium-frequency ones.

The results of this study highlight the fact that teaching collocations is one of the seemingly intractable problems in language teaching. Teachers cannot explicitly teach all the myriad collocation possibilities, yet learners need them to produce language that is appropriate and idiomatic. Although there have been some fledgling attempts to devise methodologies for teaching collocations (e.g., Lewis, 2000; Schmitt \& Schmitt, 2005), they are nowhere close to offering a satisfying solution. Wray (2002) suggests that the development of good collocation intuitions comes down to how language is learned. Native speakers appear to learn formulaic language throughout the language acquisition process, while NNSs focus more on individual words than on sequences because words are more manageable and give learners a feeling of control over the language. 
The consequence [of focusing on word-sized units in L2 learning] is a failure to value the one property of nativelike input which is most characteristic of the idiomaticity to which the learner ultimately aspires: words do not go together, having first been apart, but, rather, belong together, and do not necessarily need separating. (Wray, 2002, p. 212)

Perhaps the only way to develop good collocation intuitions in our learners is to institute a fundamental change in our teaching pedagogies, moving from a focus on individual words toward a focus on phrasal elements.

This would probably also involve explicitly directing learners' attention to those phrasal elements. Schmidt (1990) argues that a degree of awareness of a particular item is important before the material can be incorporated into a developing interlanguage system. He further concludes that noticing is the necessary and sufficient condition for converting input into intake. In a similar vein, Nation (2001) maintains that learners need to notice a word or a word combination in written and spoken input and be aware of it as a useful language item. Schmidt and Frota (1986) claim that in order for noticed input to become intake, learners have to carry out a comparison between the forms they have produced and the forms that appear in their input. Not all learners, however, are mature enough language users to be able to analyze either what they hear or read or what they actually produce. No doubt, the more frequent the word is, the more likely it is to be encountered in the input and subsequently used productively by the learner. All common collocations used in the study have either medium (21-100) or high (>100) BNC frequency. However, as Study 2 and Study 3 demonstrate, learners tend to underestimate the commonness of frequent adjective-noun collocations, which suggests that they may not always notice collocations in their input. As Wray (2002) argues, learners do not seem to pay attention to collocational relationships; it thus appears important for teachers to make these relationships more salient and explicit.

Finally, our results challenge the idea of inadequacy of NS intuitions regarding collocation. Several researchers (Sinclair, 1991; Stubbs, 1995, 1996; Wray, 2002) have suggested that NSs do not have good intuitions as to what is common or typical in their language. It is now largely assumed that corpora are the only reliable evidence that should be used in both language research and language teaching. However, our study has demonstrated good NS intuitions: NS results showed substantial correlations with the BNC frequency in both the online and off-line tasks, and this finding applies equally to common and 
uncommon collocations and to collocations with less obvious differences in frequency, that is, medium- and high-frequency collocations. It is undeniably true that corpora are very useful in identifying the most frequent and representative collocations to be incorporated in teaching materials and tests. However, teachers (at least, native-speaking teachers) should also be able to trust their intuitions about collocation in general.

Anna Siyanova is a research student at the University of Nottingham. Her research interests lie in the area of formulaic language and its production and processing by native speakers and proficient bilinguals.

Contact: aexas7@nottingham.ac.uk

Norbert Schmitt teaches applied linguistics and vocabulary studies at the University of Nottingham. He has published widely on all aspects of second language vocabulary, and is currently writing a manual on vocabulary research techniques for Palgrave Press.

Contact: norbert.schmitt@nottingham.ac.uk

\section{Acknowledgements}

We would like to thank the three anonymous $C M L R$ reviewers for their helpful comments on previous versions of this paper.

\section{Notes}

1 Our thanks to Ali Hassiri, a graduate of the University of Nottingham School of Computer Science, for developing the software for our data collection.

2 One CMLR reviewer insightfully pointed out that L1 may have had an influence on NNS performance in Study 3. It is known that cognates appear to be processed more easily than non-cognates in an L2 (e.g., Lotto \& de Groot, 1998; Kroll, Michael, Tokowicz, \& Dufour, 2002), and this may have also been the case in our study. Although we did not address this issue here, the role of cognateness is worth exploring in future collocation research.

\section{References}

Adolphs, S., \& Durow, V. (2004). Social-cultural integration and the development of formulaic sequences. In N. Schmitt (Ed.), Formulaic sequences (pp. 107-126). Amsterdam: John Benjamins. 
Bahns, J., \& Eldaw, M. (1993). Should we teach EFL students collocations? System, 21, 101-114.

Balota, D.A. (1994). Visual word recognition: The journey from features to meaning. In M.A. Gernsbacher (Ed.), Handbook of psycholinguistics (pp. 303-358). San Diego, CA: Academic Press.

Benson, M., Benson, E., \& Ilson, R. (1997). The BBI dictionary of English word combinations. Amsterdam: John Benjamins.

Biskup, D. (1992). L1 influence on learners' renderings of English collocations: A Polish/German empirical study. In P.J.L. Arnaud \& H. Béjoint (Eds.), Vocabulary and applied linguistics (pp. 85-93). Basingstoke, UK: Macmillan.

Conklin, K., \& Schmitt, N. (in press). Formulaic sequences: Are they processed more quickly than nonformulaic language by native and nonnative speakers? Applied Linguistics.

Cowie, A.P. (1998). Phraseology: Theory, analysis, and applications. Oxford: Oxford University Press.

Dörnyei, Z., Durow, V., \& Zahran, K. (2004). Individual differences and their effects on formulaic sequence acquisition. In N. Schmitt (Ed.), Formulaic sequences (pp. 87-106). Amsterdam: John Benjamins.

Ellis, N.C. (2002). Frequency effects in language processing. Studies in Second Language Acquisition, 24(2), 143-188.

Erman, B., \& Warren, B. (2000). The idiom principle and the open-choice principle. Text, 20, 29-62.

Evert, S., \& Krenn, B. (2001, July). Methods for the qualitative evaluations of lexical association measures. Paper presented at the 39th Annual Meeting of the Association for Computational Linguistics, Toulouse, France.

Farghal, M., \& Obiedat, H. (1995). Collocations: A neglected variable in EFL. International Review of Applied Linguistics, 33, 315-331.

Foster, P. (2001). Rules and routines: A consideration of their role in the task-based language production of native and non-native speakers. In M. Bygate, P. Skehan, \& M. Swain (Eds.), Researching pedagogic tasks: Second language learning, teaching and testing (pp. 75-93). Harlow, UK: Longman.

Gibbs, R., Bogdanovich, J., Sykes, J., \& Barr, D. (1997). Metaphor in idiom comprehension. Journal of Memory and Language, 37(2), 141-154.

Granger, S. (1998). Prefabricated patterns in advanced EFL writing: Collocations and formulae. In A.P. Cowie (Ed.), Phraseology: Theory, analysis, and applications (pp. 79-100). Oxford: Oxford University Press.

Granger, S., Dagneaux, E., \& Meunier, F. (Eds.). (2002). International corpus of learner English. Louvain: Presses Universitaires de Louvain.

Granger, S., Sanders, C. \& Connor, U. (n.d.). LOCNESS: Louvain corpus of native English essays. Retrieved December 27, 2007, from http://www.fltr.ucl. ac.be/fltr/germ/etan/cecl/Cecl-Projects/Icle/locness1.htm. 
Harley, T.A. (2001). The psychology of language (2nd ed.). Hove, UK: Psychology Press.

Howarth, P. (1998). The phraseology of learners' academic writing. In A.P. Cowie (Ed.), Phraseology: Theory, analysis, and applications (pp. 161-186). Oxford: Oxford University Press.

Hunston, S. (2002). Corpora in applied linguistics. Cambridge: Cambridge University Press.

Kroll, J.F., Michael, E., Tokowicz, N., \& Dufour, R. (2002). The development of lexical fluency in a second language. Second Language Research, 18(2), 137-171.

Lewis, M. (Ed.). (2000). Teaching collocation. Hove, UK: Language Teaching Publications.

Lotto, L., \& de Groot, A.M.B. (1998). Effects of learning method and word type on acquiring vocabulary in an unfamiliar language. Language Learning, 48(1), 31-69.

Manning, C.D., \& Schütze, H. (1999). Foundations of statistical natural language processing. Cambridge, MA: MIT Press.

Marinis, T. (2003). Psycholinguistic techniques in second language acquisition research. Second Language Research, 19(2), 144-161.

Nation, I.S.P. (2001). Learning vocabulary in another language. Cambridge: Cambridge University Press.

Nesselhauf, N. (2003). The use of collocations by advanced learners of English and some implications for teaching. Applied Linguistics, 24, 223-242.

Nesselhauf, N. (2004). Collocations in a learner corpus. Amsterdam: John Benjamins.

Oxford collocations dictionary. (2002). Oxford: Oxford University Press.

Pawley, A., \& Syder, F.H. (1983). Two puzzles for linguistic theory: Nativelike selection and nativelike fluency. In J.C. Richards \& R.W. Schmidt (Eds.), Language and communication (pp. 191-226). London: Longman.

Schinke-Llano, L. (1990). Can foreign language learning be like second language acquisition? The curious case of immersion. In B. VanPatten \& J. Lee (Eds.), Second language acquisition-Foreign language learning (pp. 216-225). Clevedon, UK: Multilingual Matters.

Schmidt, R. (1990). The role of consciousness in second language learning. Applied Linguistics, 11, 129-158.

Schmidt, R., \& Frota, S. (1986). Developing basic conversational ability in a second language: A case-study of an adult learner. In R. Day (Ed.), Talking to learn (pp. 237-326). Rowley, MA: Newbury House.

Schmitt, D., \& Schmitt, N. (2005). Focus on vocabulary: Mastering the Academic Word List. White Plains, NY: Longman.

Segalowitz, N., \& Freed, B. (2004). Context, contact, and cognition in oral fluency acquisition. Studies in Second Language Acquisition, 26, 173-199.

(C) 2008 The Canadian Modern Language Review/La Revue canadienne des langues vivantes, 64, 3 (March/mars), 429-458 
Sinclair, J. (1991). Corpus, concordance, collocation. Oxford: Oxford University Press.

Skehan, P. (1998). A cognitive approach to language learning. Oxford: Oxford University Press.

Stubbs, M. (1995). Corpus evidence for norms of lexical collocation. In G. Cook \& B. Seidlhofer (Eds.), Principle and practice in applied linguistics: Studies in honour of H. Widdowson (pp. 245-256). Oxford: Oxford University Press.

Stubbs, M. (1996). Text and corpus analysis. Oxford: Blackwell.

Underwood, G., Schmitt, N., \& Galpin, A. (2004). The eyes have it: An eye-movement study into the processing of formulaic sequences. In N. Schmitt (Ed.), Formulaic sequences (pp. 153-172). Amsterdam: John Benjamins.

Wray, A. (2002). Formulaic language and the lexicon. Cambridge: Cambridge University Press.

Xiao, R., \& McEnery, T. (2006). Collocation, semantic prosody, and near synonymy: A cross-linguistic perspective. Applied Linguistics, 27(1), 103-129.

Yorio, C.A. (1989). Idiomaticity as an indicator of second language proficiency. In K. Hyltenstam \& L. K. Obler (Eds.), Bilingualism across the lifespan (pp. 55-72). Cambridge: Cambridge University Press. 
Copyright of Canadian Modern Language Review is the property of University of Toronto Press and its content may not be copied or emailed to multiple sites or posted to a listserv without the copyright holder's express written permission. However, users may print, download, or email articles for individual use. 